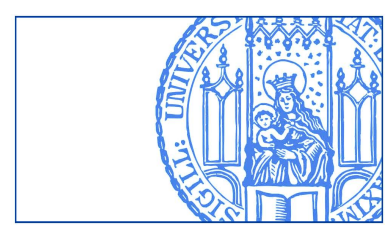

Cao, Jin und Illing, Gerhard:

Endogenous Systemic Liquidity Risk

Munich Discussion Paper No. 2008-9

Department of Economics

University of Munich

Volkswirtschaftliche Fakultät

Ludwig-Maximilians-Universität München

Online at https://doi.org/10.5282/ubm/epub.3358 


\title{
Endogenous systemic liquidity risk *
}

\author{
Jin Cao ${ }^{\mathrm{a}, \mathrm{b}}$, Gerhard Illing ${ }^{\mathrm{b}, \mathrm{c}, *}$ \\ ${ }^{a}$ Munich Graduate School of Economics (MGSE), Germany \\ ${ }^{\mathrm{b}}$ Department of Economics, University of Munich, D-80539 Munich, Germany \\ ${ }^{\mathrm{c} C E S i f o, ~ G e r m a n y ~}$
}

\begin{abstract}
Traditionally, aggregate liquidity shocks are modelled as exogenous events. Extending our previous work (Cao \& Illing, 2007), this paper analyses the adequate policy response to endogenous systemic liquidity risk. We analyse the feedback between lender of last resort policy and incentives of private banks, determining the aggregate amount of liquidity available. We show that imposing minimum liquidity standards for banks ex ante are a crucial requirement for sensible lender of last resort policy. In addition, we analyse the impact of equity requirements and narrow banking, in the sense that banks are required to hold sufficient liquid funds so as to pay out in all contingencies. We show that such a policy is strictly inferior to imposing minimum liquidity standards ex ante combined with lender of last resort policy.

JEL classification: E5, G21, G28
\end{abstract}

Key words: Liquidity risk, Free-riding, Narrow banking, Lender of last resort

\footnotetext{
‡ First version: April, 2008.

* Corresponding author. Seminar für Makroökonomie, Ludwig-MaximiliansUniversität München, Ludwigstrasse 28/012 (Rgb.), D-80539 Munich, Germany. Tel.: +49 892180 2126; fax: +49 89218013521 .

Email addresses: jin. cao@lrz . uni-muenchen.de (Jin Cao), illing@lmu.de (Gerhard Illing).
} 
The events earlier this month leading up to the acquisition of Bear Stearns by JP Morgan Chase highlight the importance of liquidity management in meeting obligations during stressful market conditions. ... The fate of Bear Stearns was the result of a lack of confidence, not a lack of capital. ... At all times until its agreement to be acquired by JP Morgan Chase during the weekend, the firm had a capital cushion well above what is required to meet supervisory standards calculated using the Basel II standard.

- Chairman Cox, SEC, Letter to Basel Committee in Support of New Guidance on Liquidity Management, March 20, 2008

Bear Stearns never ran short of capital. It just could not meet its obligations. At least that is the view from Washington, where regulators never stepped in to force the investment bank to reduce its high leverage even after it became clear Bear was struggling last summer. Instead, the regulators issued repeated reassurances that all was well. Does it sound a little like a doctor emerging from a funeral to proclaim that he did an excellent job of treating the late patient?

— Floyd Norris, New York Times, April 4, 2008

\section{Introduction}

For a long time, presumably starting in 2004, financial markets seemed to have been awash with excessive liquidity. But suddenly, in August 2007, liquidity dried out nearly completely as a response to doubts about the quality of subprime mortgage-backed securities. Despite massive central bank interventions, the liquidity freeze did not melt away, but rather spread slowly to other markets such as those for auction rate bonds. On March 16th 2008, the investment bank Bear Sterns which - according to the SEC chairman - was adequately capitalized even a week before had to be rescued via a Fed-led takeover by JP Morgan Chase. 
Following the turmoil on financial markets, there has been a strong debate about the adequate policy response. Some have warned that central bank actions may encourage dangerous moral hazard behaviour of market participants in the future. Others instead criticised central banks of responding far too cautiously. The most prominent voice has been Willem Buiter who — jointly with Ann Sibert — right from the beginning of the crisis in August 2008 strongly pushed the idea that in times of crises, central banks should act as market maker of last resort. As adoption of the Bagehot principles to modern times with globally integrated financial systems, central banks should actively purchase and sell illiquid private sector securities and so play a key role in assessing and pricing credit risk. In his FT blog "Maverecon", Willem Buiter stated the intellectual arguments behind such a policy very clearly on December 13, 2007:

"Liquidity is a public good. It can be managed privately (by hoarding inherently liquid assets), but it would be socially inefficient for private banks and other financial institutions to hold liquid assets on their balance sheets in amounts sufficient to tide them over when markets become disorderly. They are meant to intermediate short maturity liabilities into long maturity assets and (normally) liquid liabilities into illiquid assets. Since central banks can create unquestioned liquidity at the drop of a hat, in any amount and at zero cost, they should be the liquidity providers of last resort, both as lender of last resort and as market maker of last resort. There is no moral hazards as long as central banks provide the liquidity against properly priced collateral, which is in addition subject to the usual 'liquidity haircuts' on this fair valuation. The private provision of the public good of emergency liquidity is wasteful. It's as simple as that."

Just the week before the breakdown of Bear Sterns, the Fed seems to have followed Buiter's advice and increased lending against illiquid securities in exchange for Treasury securities on a massive scale. Even though central banks are still reluctant to play an active role as market maker (denying rumours of discussions about the feasibility of mass purchases of mortgagebacked securities as a possible solution), the prevailing main stream view 
seems to be that there is no moral hazard risk as long as the Bagehot principles are followed as best practice in liquidity management.

According to the Bagehot principles, a Lender of Last Resort Policy should target liquidity provision to the market, but not to specific banks. Central banks should "lend freely at a high rate against good collateral."This way, public liquidity support is supposed to be targeted towards solvent yet illiquid institutions, since insolvent financial institutions should be unable to provide adequate collateral to secure lending. This paper wants to challenge the view that a policy following Bagehot principle does not create moral hazard. The key point is this view neglects the endogeneity of aggregate liquidity risk. Starting with Allen \& Gale (1998) and Holmström \& Tirole (1998), there have been quite a few models recently analysing private and public provision of liquidity. But as far as we know, in all these models except our companion paper Cao \& Illing (2007), aggregate systemic risk is assumed to be an exogenous probability event.

In Holmström \& Tirole (1998), for instance, liquidity shortages arise when financial institutions and industrial companies scramble for, and cannot find the cash required to meet their most urgent needs or undertake their most valuable projects. They show that credit lines from financial intermediaries are sufficient for implementing the socially optimal (second-best) allocation, as long as there is no aggregate uncertainty. In the case of aggregate uncertainty, however, the private sector cannot satisfy its own liquidity needs, so the existence of liquidity shortages vindicates the injection of liquidity by the government. In their model, the government can provide (outside) liquidity by committing future tax income to back up the reimbursements.

In the model of Holmström \& Tirole (1998), the Lender of Last Resort indeed provides a free lunch: public provision of liquidity in the presence of aggregate shocks is a pure public good, with no moral hazard involved. The reason is that aggregate liquidity shocks are modelled as exogenous events; there is no endogenous mechanism determining the aggregate amount of liquidity available. The same holds in Allen \& Gale (1998), even though 
they analyse a quite different mechanism for public provision of liquidity: the adjustment of the price level in an economy with nominal contracts. We adopt Allen \& Gale's mechanism. But we show that there is no longer a free lunch when private provision of liquidity affects the likelihood of an aggregate (systemic) shock.

The basic idea of our model is fairly straightforward: Financial intermediaries can choose to invest in more or less (real) liquid assets. We model illiquidity in the following way: some fraction of projects turns out to be realised late. The aggregate share of late projects is endogenous; it depends on the incentives of financial intermediaries to invest in risky, illiquid projects. This endogeneity allows us to capture the feedback from liquidity provision to risk taking incentives of financial intermediaries. We show that the anticipation of unconditional central bank liquidity provision will encourage excessive risk taking (moral hazard). It turns out that in the absence of liquidity requirements, there will be overinvestment in risky activities, creating excessive systemic risk.

In contrast to what the Bagehot principle suggests, unconditional provision of liquidity to the market (lending of central banks against good collateral) is exactly the wrong policy: It distorts incentives of banks to provide the efficient amount of private liquidity. In our model, we concentrate on pure illiquidity risk: There will never be insolvency unless triggered by illiquidity (by a bank run). Illiquid projects promise a higher, yet possibly retarded return. Relying on sufficient liquidity provided by the market (or by the central bank), financial intermediaries are inclined to invest more heavily in high yielding, but illiquid long term projects. Central banks liquidity provision, helping to prevent bank runs with inefficient early liquidation, encourages bank to invest more in illiquid assets. At first sight, this seems to work fine, even if systemic risk increases: After all, public insurance against aggregate risks should allow agents to undertake more profitable activities with higher social return. As long as public insurance is a free lunch, there is nothing wrong with providing such a public good. 
The problem, however, is that due to limited liability some banks will be encouraged to free ride on liquidity provision. This competition will force other banks to reduce their efforts for liquidity provision, too. Chuck Prince, at that time chief executive of Citigroup, stated the dilemma posed in fairly poetic terms on July 10th 2007 in a (in-) famous interview with Financial Times $^{1}$ :

"When the music stops, in terms of liquidity, things will be complicated. But as long as the music is playing, you've got to get up and dance. We're still dancing."

The dancing banks simply enjoy liquidity provided in good states of the world and just disappear (go bankrupt) in bad states. The incentive of financial intermediaries to free ride on liquidity in good states results in excessively low liquidity in bad states. Even worse: As long as they are not run, "dancing" banks can always offer more attractive collateral in bad states - so they are able to outbid prudent banks in a liquidity crisis. For that reason, the Bagehot principle, rather than providing correct incentives, is the wrong medicine in modern times with a shadow banking system relying on liquidity being provided by other institutions.

This paper extends a model developed in Cao \& Illing (2007). In that paper we did not allow for banks holding equity, so we could not analyse the impact of equity requirements. As we will show, imposing equity requirements can be inferior even relative to the outcome of a mixed strategy equilibrium with free riding (dancing) banks. In contrast, imposing binding liquidity requirements combined with a strict central bank commitment not

1 The key problem is best captured by the following remark about Citigroup in the New York Times report "Treasury Dept. Plan Would Give Fed Wide New Power" on March 29, 2008: "Mr. Frank said he realized the need for tighter regulation of Wall Street firms after a meeting with Charles O. Prince III, then chairman of Citigroup. When Mr. Frank asked why Citigroup had kept billions of dollars in 'structured investment vehicles'off the firm's balance sheet, he recalled, Mr. Prince responded that Citigroup, as a bank holding company, would have been at a disadvantage because investment firms can operate with higher debt and lower capital reserves." 
to support dancing banks is able to implement the optimal second best outcome. In our two state model capital requirements turn out to be equivalent to "narrow banking"(banks being required to hold sufficient equity so as to be able to pay out demand deposits in all states of the world). So we also prove that narrow banking is likely to be inferior even relative to a highly volatile banking system facing strong systemic risk.

Allen \& Gale (2007, p 213f) notice that the nature of market failure leading to systemic liquidity risk is not yet well understood. They argue that "a careful analysis of the costs and benefits of crises is necessary to understand when intervention is necessary."In this paper, we try to fill this gap, providing a cost / benefit analysis of different forms of banking regulation to better to understand what type of intervention is required. We explicitly compare the impact both of liquidity and capital requirements. To the best of our knowledge, this is the first paper providing such an analysis.

Our argument also seems to be valid for the modelling approach used in Goodfriend \& McCallum (2007). They introduce a banking sector in the standard New Keynesian framework to reconsider the role of money and banking in monetary policy analysis. Goodfriend \& McCallum show that "banking accelerator"transmission effects work via an "external finance premium."In their model, the central bank should react more aggressively to problems in the banking sector. This result may need to be qualified if these problems within the banking sector are generated endogenously rather than being the result of exogenous shocks.

\section{The structure of the model}

In the economy, there are three types of agents: investors, banks (run by bank managers) and entrepreneurs. All agents are risk neutral. The economy extends over 3 periods. We assume that there is a continuum of investors each initially (at $t=0$ ) endowed with one unit of resources. The resource 
can be either stored (with a gross return equal to 1) or invested in the form of bank equity or bank deposits. Using these funds, banks as financial intermediaries can fund projects of entrepreneurs. There are two types $i$ of entrepreneurs $(i=1,2)$, characterised by their projects return $R_{i}$. Project of type 1 are realised early at period $t=1$ with a safe return $R_{1}>1$. Project of type 2 give a higher return $R_{2}>R_{1}>1$. With probability $p$, these projects will also be realised at $t=1$, but they may be delayed (with probability $1-p$ ) until $t=2$. In the aggregate, the share $p$ of type 2 projects will be realised early. The aggregate share $p$, however is not known at $t=0$. It will be revealed between 0 and 1 at some intermediate period $t=\frac{1}{2}$. Investors are impatient: They want to consume early (at $t=1$ ). In contrast, both entrepreneurs and bank managers are indifferent between consuming early $(t=1)$ or late $(t=2)$.

Resources of investors are scarce in the sense that there are more projects of each type available than the aggregate endowment of investors. Thus, in the absence of commitment problems, total surplus would go to the investors. In the absence of commitment problems, investors would simply put all their funds in early projects and capture the full return. We take this first-best market outcome as reference point and analyse those equilibria coming closest to implement the market outcome.

Due to hold up problems as modelled in Hart \& Moore (1994), entrepreneurs can only commit to pay a fraction $\gamma R_{i}>1$ of their return. Banks as financial intermediaries can pool investment; they also have superior collection skills (a higher $\gamma$ ). Following Diamond \& Rajan (2001), banks offer deposit contracts with a fixed payment $d_{0}$ payable at any time after $t=0$ as a credible commitment device not to abuse their collection skills. The threat of a bank run disciplines bank managers to fully pay out all available resources pledged in the form of bank deposits. In the absence of aggregate risk, financial intermediation via bank deposits can implement a second best allocation, given the hold up problem posed by entrepreneurs.

Note that because of the hold up problem, entrepreneurs retain a rent 
- their share $(1-\gamma) R_{i}$. Since early entrepreneurs are indifferent between consuming at $t=1$ or $t=2$, they are willing to provide liquidity (using their rent to buy equity shares and to deposit at banks at $t=1$ at the market rate $r$ ). Banks use the liquidity provided to pay out depositors. This way, impatient investors can profit indirectly from investment in high yielding long term projects. So banking allows transformation between liquid claims and illiquid projects.

At date 0 , banks competing for funds offer deposit contracts with payment $d_{0}$ and equity claims which maximise expected consumption of investors at the given expected interest rates. Investors put their funds into those assets promising the highest expected return among all assets offered. So in equilibrium, expected return from deposits and equity must be equal across all active banks. At date $t=1$, banks and early entrepreneurs trade at a perfect market for liquidity, clearing at interest rate $r$. As long as banks are liquid, the payoff structure is described as in Figure 1.

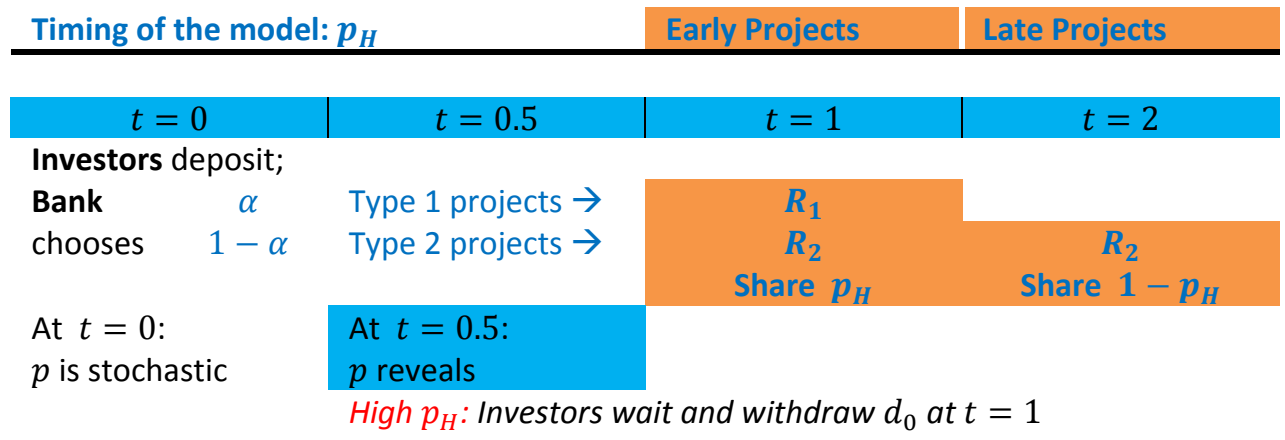

Fig. 1. Timing and payoff structure, when banks are liquid

Deposit contracts, however, introduce a fragile structure into the economy: Whenever depositors have doubts about their bank's liquidity (the ability to pay depositors the promised amount $d_{0}$ at $t=1$ ), they run the bank early (they run already at the intermediate date $t=\frac{1}{2}$ ), forcing the bank to liquidate all its projects (even those funding safe early entrepreneurs) at high costs: Early liquidation of projects gives only the inferior return $c<1$. We do not consider pure sunspot bank runs of the Diamond \& Dybvig type. 
Instead we concentrate on runs happening if liquid funds (given the interest rate $r$ ) are not sufficient to payout depositors.

If the share $p$ of type 2 projects realised early is known at $t=0$, there is no aggregate uncertainty. Banks will invest such that - on aggregate they are able to fulfil depositor's claims in period 1, so there will be no run. But we are interested in the case of aggregate shocks. We model them in the simplest way: the aggregate share of type 2 projects realised early can take on just two values: either $p_{H}$ or $p_{L}$ with $p_{H}>p_{L}$. The "good"state with a high share of early type 2 projects (the state with plenty of liquidity) will be realised with probability $\pi$. Note that the aggregate liquidity available depends on the total share of funds invested in liquid type 1 projects. Let $\alpha$ be this share. If $\alpha$ is so low that banks cannot honor deposits when $p_{L}$ occurs, depositors will run at $t=\frac{1}{2}$. The payoff is captured in FIgURE 2.

\begin{tabular}{|c|c|c|}
\hline \multicolumn{2}{|c|}{ Timing of the model: $p_{L}$} & Liquidation at $t=0.5$ \\
\hline$t=0$ & $t=0.5$ & $t=2$ \\
\hline \multicolumn{3}{|l|}{ Investors deposit; } \\
\hline Bank $\quad \alpha$ & Type 1 projects $\rightarrow$ & $c$ \\
\hline chooses & Type 2 projects $\rightarrow$ & $c$ \\
\hline \multirow[t]{2}{*}{$\begin{array}{l}\text { At } t=0: \\
p \text { is stochastic }\end{array}$} & $\begin{array}{l}\text { At } t=0.5: \\
p \text { reveals }\end{array}$ & \\
\hline & $p_{L}:$ Investors run & $\begin{array}{l}\text { All projects are } \\
\text { liquidated at } \\
t=0.5 \\
\text { Return } c<1\end{array}$ \\
\hline
\end{tabular}

Fig. 2. Timing and payoff structure, when banks are illiquid

Given this structure, a bank seems to have just two options available: it can either invest so much in safe type 1 projects that it will be able to pay out its depositors all the time (that is, even if the bad state occurs). Let us call this share $\alpha\left(p_{L}\right)$. Alternatively, it may invest just enough, $\alpha\left(p_{H}\right)$, so as to pay out depositors in the good state. If so, the bank will be run in the bad state. Obviously, the optimal share depends on what other banks will do (since that determines aggregate liquidity available at $t=1$ and so the interest 
rate for liquid funds between period 1 and 2), but also on the probability $\pi$ for the good state. To gain some intuition, let us first assume that all banks behave the same - just as a representative bank. If so, it will not pay to take precautions against the bad state if the likelihood for that outcome is considered to be very low. Thus, if $\pi$ is very high, the representative bank will obviously invest only a small share $\alpha\left(p_{H}\right)$ - just enough to pay out depositors in the good state. Alternatively, if $\pi$ is very low (close to 0 ), it always pays to be prepared for the worst case, so the representative bank will invest a high share $\alpha\left(p_{L}\right)>\alpha\left(p_{H}\right)$ in safe projects. Since $\alpha\left(p_{s}\right)$ is the share invested in safe projects with return $R_{1}$, the total payoff out of investment strategy $\alpha\left(p_{s}\right)$ is: $E\left[R_{s}\right]=\alpha\left(p_{s}\right) R_{1}+\left[1-\alpha\left(p_{s}\right)\right] R_{2}$ with $E\left[R_{H}\right]>E\left[R_{L}\right]$.

With a high share $\alpha\left(p_{L}\right)$ of safe projects, the banks will be able to pay out depositors in all states. There will never be a bank run. So the expected payoff for depositors is $\gamma E\left[R_{L}\right]$ (assuming that the gross interest rate between $t=1$ and $t=2$ is $r=1$, which is the case maximising the investors payoffs).

With $\alpha\left(p_{H}\right)$ there will be a bank run in the bad state, giving just the bankruptcy payoff $c$ with probability $1-\pi$. So strategy $\alpha\left(p_{H}\right)$ gives $\pi \gamma E\left[R_{H}\right]+$ $(1-\pi) c$. Depositors prefer $\alpha\left(p_{H}\right)$, if $\pi \gamma E\left[R_{H}\right]+(1-\pi) c>\gamma E\left[R_{L}\right]$ or

$$
\pi>\bar{\pi}_{2}=\frac{\gamma E\left[R_{L}\right]-c}{\gamma E\left[R_{H}\right]-c} .
$$

Obviously, for $\pi$ below $\bar{\pi}_{2}$ depositors are better off with the safe strategy, so they prefer banks to choose $\alpha\left(p_{L}\right)$ rather than to exploit high profitability of type 2 entrepreneurs. The intuition is straightforward: When $\pi$ is not high enough, the high return $R_{2}$ will come too late most of the time, triggering frequent bank runs in period 1. So depositors rather prefer banks to play the safe strategy in the range. In contrast, for $\pi>\bar{\pi}_{2}$ it would be socially inefficient for private banks to hold enough liquid assets on their balance sheets to prevent disaster when markets become disorderly. As long as all banks play according to the strategies outlined above, depositors payoff is characterised by the red line in FIgURE 3. 


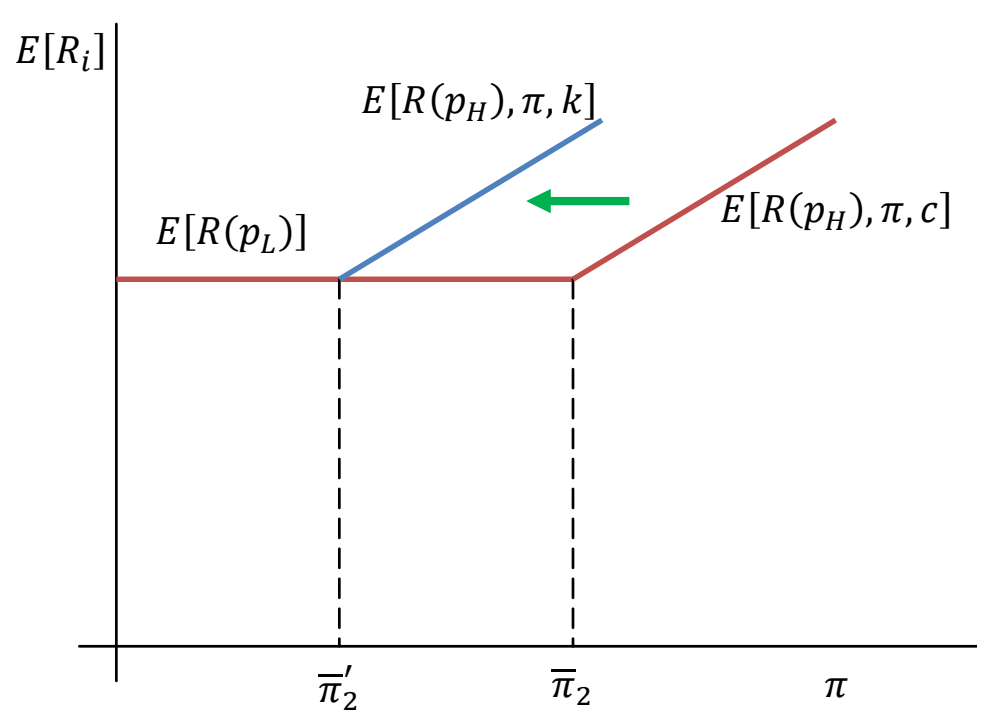

Fig. 3. Depositors' expected return

Central bank intervention could help to improve on that outcome. This is easiest to see if deposit contracts are arranged in nominal terms. Consider that the central bank injects liquidity in order to prevent bank runs if the bad state (with low payoffs at $t=1$ ) occurs. Following Allen \& Gale (1998) and Diamond \& Rajan (2006), assume that the liquidity injection is done such that the banks are able to honour their nominal contracts, reducing the real value of deposits just to the amount of real resources available. This intervention raises the real payoff of depositors compared to inefficient liquidation, shifting the expected payoff of the risky strategy $\alpha\left(p_{H}\right)$ to the left (as indicated by the blue line in Figure 3). Essentially, nominal deposits allow the central bank to implement state contingent payoffs as a public good: The injection of additional liquidity helps to prevent bank runs.

In that sense, lender of last resort activity preventing costly bank runs would definitely raise expected welfare, even though it increases the range of parameter values with systemic risk: Anticipating central bank intervention, banks would choose $\alpha\left(p_{H}\right)$ for a wider range of $\pi$ : for $\pi>\bar{\pi}_{2}^{\prime}$ rather than for $\pi>\bar{\pi}_{2}$.

This reasoning seems to support the argument that lender of last resort 
indeed is a free lunch, providing a public good at no cost. Unfortunately, a closer look at the equilibrium outcome tells us that this argument is wrong, for the following reason:

Up to now, we simply assumed that all banks follow the same strategy, maximising depositor's payoff. When all banks choose the strategy $\alpha\left(p_{L}\right)$, there will be excess liquidity at $t=1$ if the good state occurs (with a large share of type 2 projects realised early). A bank anticipating this event has a strong incentive to invest all their funds in type 2 projects, reaping the benefit of excess liquidity in the good state. As long as the music is playing, such a deviating bank gets up and dances. Having invested in high yielding projects, the dancing bank can always credibly extract entrepreneur's excess liquidity at $t=1$, promising to pay back at $t=2$ out of highly profitable projects. After all, at that stage, this bank, free riding on liquidity, can offer a capital cushion with expected returns well above what prudent banks are able to promise. Of course, if the bad state happens, there is no excess liquidity. The "dancing"banks would just bid up the interest rates, urgently trying to get funds. Rational depositors, anticipating that these banks won't succeed, will already trigger a bank run on these banks at $t=\frac{1}{2}$.

When the music stops, in terms of liquidity, things get complicated. As long as dancing banks are not supported in the bad state, they are driven out of the market, providing just the return $c$. Nevertheless, a bank free riding on liquidity in the good state can on average offer the attractive return $\pi \gamma R_{2}+(1-\pi) c$ as expected payoff for depositors. Thus, a free riding bank will always be able to outbid a prudent bank whenever the probability $\pi$ for the good state is not too low. The condition is

$$
\pi>\bar{\pi}_{1}=\frac{\gamma E\left[R_{L}\right]-c}{\gamma R_{2}-c} .
$$

Since $R_{2}>E\left[R_{H}\right]$, it pays to dance within the range $\bar{\pi}_{1} \leq \pi<\bar{\pi}_{2}$.

Obviously, there cannot be equilibrium in pure strategies. As long as the music is playing, all banks would like to get up and dance. But then, 
there would be no prudent bank left providing the liquidity needed to be able to dance. In the resulting mixed strategy equilibrium, a proportion of banks behave prudent, investing some amount $\alpha_{s}<\alpha\left(p_{L}\right)$ in liquid assets, whereas the rest free rides on liquidity in the good state, choosing $\alpha=0$. Prudent banks reduce $\alpha_{s}<\alpha\left(p_{L}\right)$ in order to cut down the opportunity cost of investing in safe projects. Interest rates and $\alpha_{s}$ adjust such that depositors are indifferent between the two types of banks. At $t=0$, both prudent and dancing banks offer the same expected return to depositors. The proportion of free-riding banks is determined by aggregate market clearing conditions in both states. Dancing banks are run for sure in the bad state, but the high return $R_{2}>E\left[R_{s}\right]$ compensates depositors for that risk.

As shown in Proposition 2.1, free-riding drives down the return for investors. They are definitely worse off than if all banks would coordinate on the prudent strategy $\alpha\left(p_{L}\right)$. As illustrated in FIGURE 4 , the effective return on deposits for investors deteriorates in the range $\bar{\pi}_{1} \leq \pi<\bar{\pi}_{2}$ as a result of free riding behaviour.

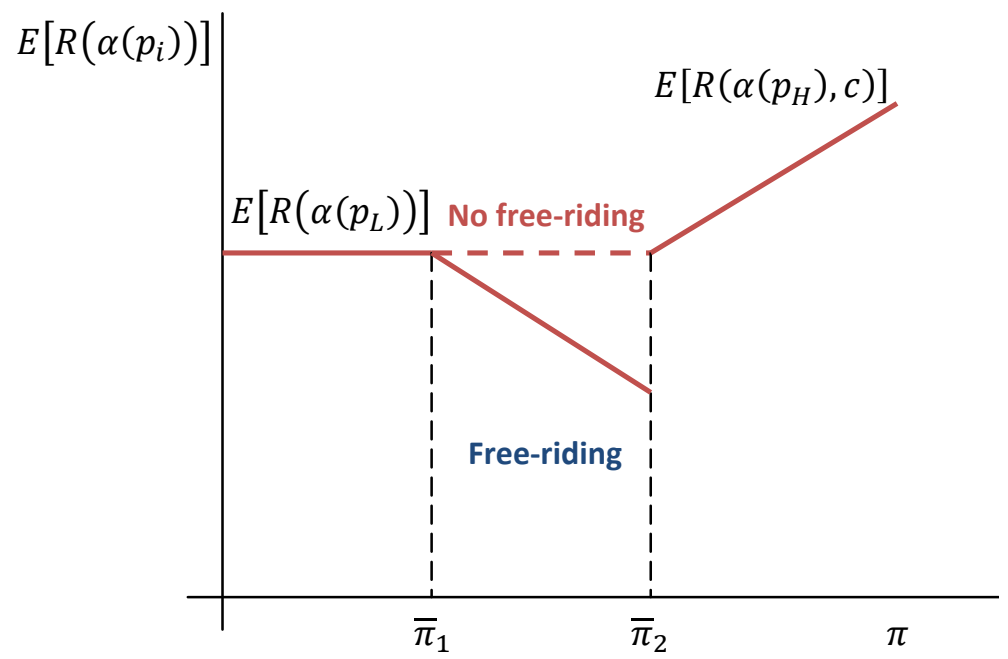

Fig. 4. Depositors' expected return with free-riding

Proposition 2.1 In the mixed strategy equilibrium, investors are worse off than if all banks would coordinate on the prudent strategy $\alpha\left(p_{L}\right)$.

Proof See Appendix A.1. 


\section{Central bank intervention}

The crucial challenge is to characterise the adequate policy response when systemic liquidity risk is endogenous. The problem is that this event is likely to result in second or rather third best options, for the simple reason that liquidity provision usually has to cope with a combination of different types of externalities. As illustrated in Figure 3, a lender of last resort preventing inefficient costly liquidation could improve upon the allocation as long as its actions would not have an impact on the amount of aggregate liquidity provided by the private sector itself. The incentive for free riding prevalent in modern times of competitive financial markets, however, complicates the picture dramatically. In the model presented, a lender of last resort, providing liquidity support to the market requesting good collateral as the only condition, will drive out all prudent banks. Just as in Gresham's law, all banks are encouraged to dance, knowing that they can get liquidity support against good collateral. The public provision of emergency liquidity results in serious moral hazard. It's as simple as that.

Proposition 3.1 Assume that $\pi p_{H} R_{2}+(1-\pi) c \geq 1$ and that for $\pi \in\left(\bar{\pi}_{1}, \bar{\pi}_{2}\right)$, $d_{0}^{j}=\gamma R_{2}>\pi p_{H} R_{2}+(1-\pi) c$. If the central bank is willing to provide liquidity to the entire market in times of crisis, all banks have an incentive to dance, choosing $\alpha_{j}=0$.

Proof See Appendix A.2.

The reason for this surprising result is the following: By purpose, we concentrate on the case of pure illiquidity risk. In our model, the liquidity shock just retards the realisation of high yielding projects: In the end (at $t=2$ ), all projects will certainly be realised. So there is no doubt about solvency of the projects, unless insolvency is triggered by illiquidity. Central bank support against allegedly good collateral, creating artificial liquidity at the drop of a hat, destroys all private incentives to care about ex ante liquidity provision. The key problem with the Bagehot principle here is that 
dancing banks do invest in projects with higher return, as long as they have not to be terminated. In reality, there is no clear-cut distinction between insolvency and illiquidity. We leave it to future research to allow for the risk of insolvency. But we doubt that our basic argument will be affected.

So what policy options should be taken? One might argue that a central bank should provide liquidity support only to prudent banks (so conditional on banks having invested sufficiently in liquid assets). As shown in Cao \& Illing (2007), such a policy may improve the allocation at least to some extent. But as we argued, such a commitment is simply not credible: There is a serious problem of dynamic consistency.

Rather than relying on an implausible commitment mechanism, the obvious solution would be a mix between two instruments. It seems to be rather surprising that perceived wisdom argues that central banks can pursue both price stability and financial stability using just one tool, interest rate policy. Instead, in a first step, a banking regulator would have to impose ex ante liquidity requirements. Requesting minimum investment in liquid type 1 assets of at least $\alpha\left(p_{L}\right)$ for $\pi<\bar{\pi}_{2}^{\prime}$ would help to implement the second best efficient allocation as characterised in FIGURE 3. Such a rule would be sufficient to get rid of incentives for free riding. For $\pi>\bar{\pi}_{2}^{\prime}$, requesting liquid assets as low as $\alpha\left(p_{H}\right)$ would be sufficient. Given that the ex ante imposed liquidity requirements have been fulfilled, ex post the central bank can safely play its role as lender in the range $\pi>\bar{\pi}_{2}^{\prime}$ whenever the bad state turns out to be realised.

The key task for regulators and the central bank is to cope with free riding incentives. An alternative mechanism compared to ex ante liquidity regulation, the central bank might commit to try to mop up the excess liquidity available in the good state. If that can be done, potential free riders would have no chance to survive. We doubt, however, that the central will be able to implement such a policy. 
As further alternative, one might impose narrow banking in the sense that banks are required to hold sufficient liquid funds so as to pay out in all contingencies. Finally, one might expect that imposing equity or capital requirements are sufficient to provide a cushion against liquidity shocks. Both these options turn out to be equivalent within our simple two state model. As the next section shows, they are strictly worse than imposing minimum liquidity standards ex ante combined with lender of last resort policy and are even likely to be inferior relative to the outcome of a mixed strategy equilibrium with free riding (dancing) banks.

\section{The role of equity}

Let us now introduce capital requirements in the model, i.e. banks are required to hold some equities in their assets. Keep the same settings as before with the presence of aggregate uncertainty, except that instead of pure fixed deposit contract, the banks issue a mixture of deposit contract and equity for the investors (Diamond \& Rajan, 2000, 2005, 2006). To make it clear, equity is a claim that can be renegotiated such that the bankers and the capital holders (here the investors) split the residual surplus after the deposit contract has been paid. The mixture of deposit contract and equity seems to be a quite artificial setting at the first sight. But actually it turns out to be a convenient modelling device. In particular, in the symmetric equilibria of the banks, such a mixture will exactly be the portfolio held by a representative agent out of the homogenous investors. In other words, whenever investors are homogenous, it's not necessary to separate equity holders from the depositors.

Capital (equity) can reduce the fragility, but it allows the bank manager to capture a rent. Being a renegotiatable claim, equity is always subject to the hold-up problem, i.e. equity holders can only get a share of $\zeta(\zeta \in[0,1])$ from the surplus. To make it simpler, in the following we simply assume that $\zeta=\frac{1}{2}$. 
With $\zeta=\frac{1}{2}$ the bankers get a rent of $\frac{\gamma E[R]-d_{0}}{2}$, sharing the surplus over deposits equally with the equity holders. Suppose that all the banks have to meet the level of equity $k$ which comes from the central bank's regulatory rules, then if a bank $i$ is not run $k$ is defined as

$$
k=\frac{\frac{\gamma E\left[R_{s, i}\right]-d_{0, i}}{2}}{\frac{\gamma E\left[R_{s, i}\right]-d_{0, i}}{2}+d_{0, i}}
$$

in which $R_{s, i}$ is bank $i^{\prime}$ s return achieved under state $s$.

One additional, but crucial assumptions concerning timing are that (1) the dividend of the equity is paid after the payment of $d_{0, i}$ and (2) capital requirement has to be met till the last minute before the dividend payment - This deters the bankers' incentive to transfer their dividend income to the investors ex post, which increases $d_{0, i}$ ex ante.

Solve for $d_{0, i}$ to get

$$
d_{0, i}=\frac{1-k}{1+k} \gamma E\left[R_{s, i}\right]
$$

Then one would ask: Under what conditions would it make sense to introduce equity requirements? It is easy to see that introducing equity will definitely reduce welfare in the absence of aggregate risk. Somewhat counterintuitive, capital requirements even reduces the share $\alpha$ invested in the safe project in that case. The reason is that with equity, bankers get a rent of $\frac{\gamma E[R]-d_{0}}{2}$, sharing the surplus over deposits equally with the equity holders. So investors providing funds in form of both deposits and equity to the banks will get out at $t=1$ just $\frac{1}{1+k} \gamma E[R]<\gamma E[R]$. Since return at $t=2$ is higher than at $t=1$, bankers prefer to consume late, so the amount of resources needed at $t=1$ is lower in the presence of equity. Consequently, the share $\alpha$ will be reduced. Of course, banks holding no equity provide more attractive conditions for investors, so equity could not survive. This at first sight counterintuitive result simply demonstrates that there is no role 
(or rather only a welfare reducing role) for capital holding in the absence of aggregate risk.

But when there is aggregate risk, equity helps to absorb the aggregate shock. In the simple 2-state set up, equity holdings need to be just sufficient to cushion the bad state. So with equity, the bank will chose $\alpha^{*}=\alpha\left(p_{H}\right)$. The level of equity $k$ needs to be so high that, given $\alpha^{*}=\alpha\left(p_{H}\right)$, the bank just stays solvent in the bad state - it is just able to payout the fixed claims of depositors, whereas all equity will be wiped out.

With equity $k$, the total amount that can be pledged to both depositors and equity in the good state is $\frac{1}{1+k} \gamma E\left[R_{H}\right]$ with claims of depositors being $d_{0}=\frac{1-k}{1+k} \gamma E\left[R_{H}\right]$ and equity $E Q=\frac{k}{1+k} \gamma E\left[R_{H}\right]$. In the bad state, a marginally solvent bank can pay out to depositors $d_{0}=\alpha\left(p_{H}\right) R_{1}+\left(1-\alpha\left(p_{H}\right)\right) p_{L} R_{2}$. So $k$ is determined by the condition:

$$
\frac{1-k}{1+k} \gamma E\left[R_{H}\right]=\alpha\left(p_{H}\right) R_{1}+\left(1-\alpha\left(p_{H}\right)\right) p_{L} R_{2}
$$

and solve to get

$$
k=\frac{\gamma E\left[R_{H}\right]-d_{0}}{\gamma E\left[R_{H}\right]+d_{0}}
$$

It's observed that $k$ is decreasing in $p_{L}$ : the higher $p_{L}$, the lower the equity $k$ needed to stay solvent in the bad state. $k=0$ for $p_{L}=p_{H}$, and for $p_{L}$ close to $p_{H}$ equity holding is superior to the strategy $\alpha^{*}=\alpha\left(p_{H}\right)$. That is if

$$
d_{0} \geq \gamma E\left[R_{H}\right] \pi+(1-\pi) c
$$

Such $\left(d_{0}, k\right)$ is the equilibrium for the banks. The reason is easy to see: First, no banks are willing to set higher $k_{i}$ - because equity holding is costly and she is not able to compete the other banks for $\left(d_{0, i}, k_{i}\right)$; Second, no banks are able to set higher $d_{0, i}$ given $\left(d_{0}, k\right)$ set by all the other banks - because $k$ has 
to be met when $d_{0, i}$ is paid, the only thing the deviator can do is to bid up interest rate and this leads to bank runs across the whole banking industry - the deviation is not profitable.

From the regulator's point of view, the unique optimal equity requirement $k$ it imposes is exactly the $k$ determined by condition (1), which is so high that the bank just stays solvent in the bad state - it is just able to payout the fixed claims of depositors, whereas all equity will be wiped out. The reason is simple: Since equity holding is costly, the only reason for the central bank to make it sensible is to eliminate the costly bank run. Therefore neither too low $k$ (which is purely a cost and doesn't prevent any bank run) nor too high $k$ (which prevent bank runs, but incurs a too high cost of holding capital) is optimal. Thus from now on we can concentrate on such level of $k$ without loss of generality.

Now the interesting question is: Can capital requirement improve the allocation in this economy, in comparison to the laissez-faire outcome we studied before?

Definition Define a representative depositor's expected return function without equity requirements as $\Pi(\pi, \cdot)$, such that

$$
\Pi(\pi, \cdot)= \begin{cases}\gamma E\left[R_{L}\right], & \text { if } \pi \in\left[0, \bar{\pi}_{1}\right] ; \\ \alpha_{s}^{*} R_{1}+\left(1-\alpha_{s}^{*}\right) p_{L} R_{2}, & \text { if } \pi \in\left(\bar{\pi}_{1}, \bar{\pi}_{2}\right) ; \\ \gamma E\left[R_{H}\right] \pi+(1-\pi) c, & \text { if } \pi \in\left[\bar{\pi}_{2}, 1\right]\end{cases}
$$

and her expected return function under equity requirements as $\Pi_{e}(\pi, \cdot)$, as well as the set $S$ in which the depositor's welfare is improved under equity requirement, such that

$$
S:=\left\{\hat{\pi} \mid \Pi_{e}(\hat{\pi}, \cdot) \geq \Pi(\hat{\pi}, \cdot)\right\}
$$




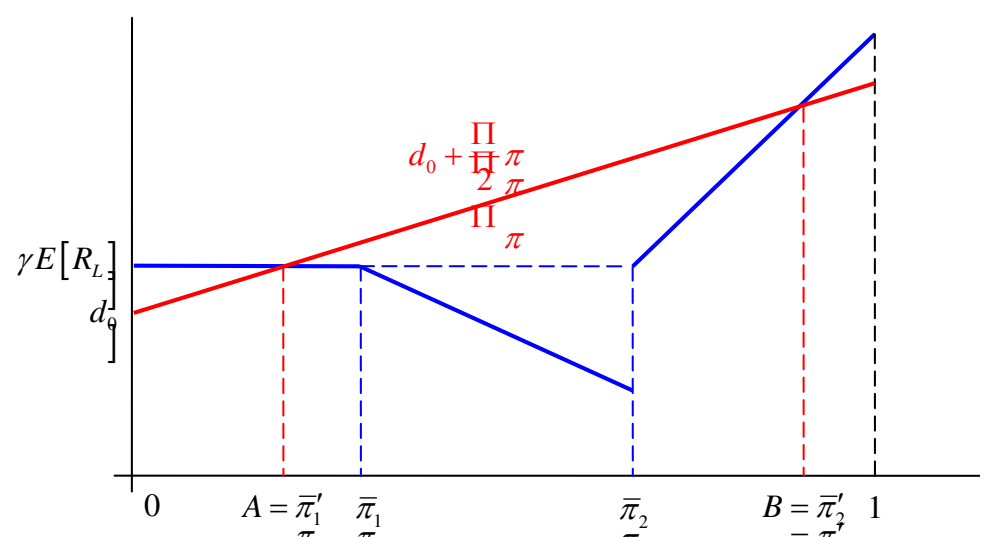

Fig. 5. Expected return with / without equity - Case 1

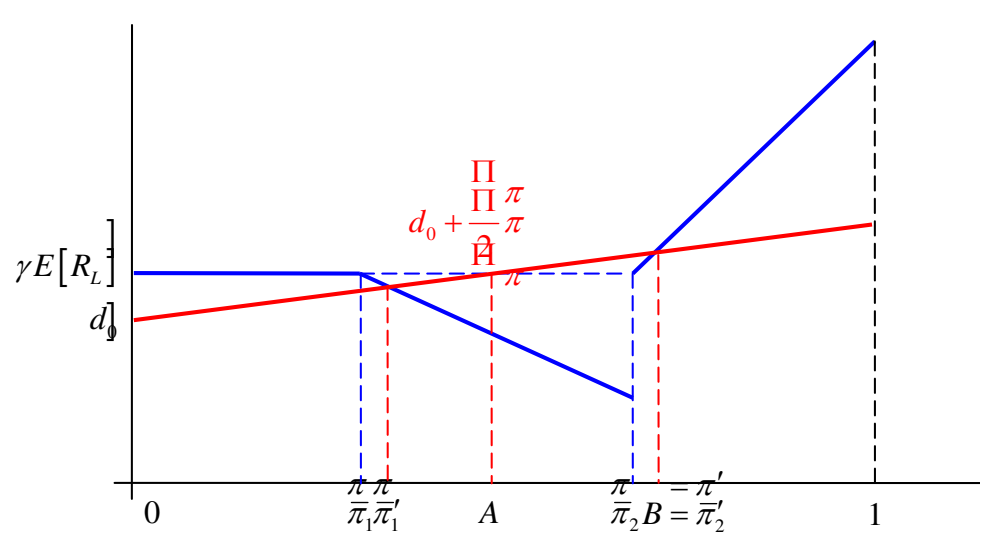

Fig. 6. Expected return with / without equity - Case 2

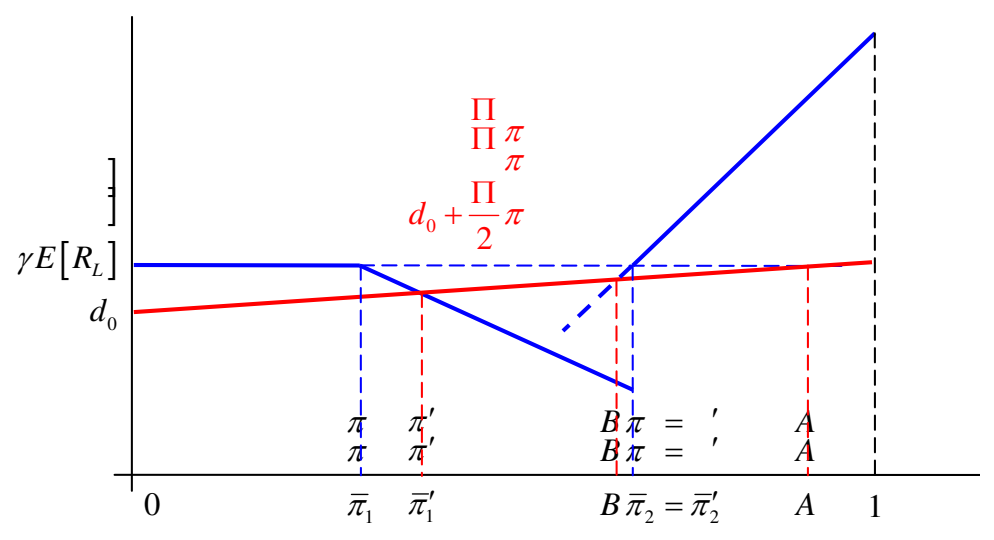

Fig. 7. Expected return with / without equity - Case 3

The blue lines of Figure 5 describe the laissez-faire outcome $\Pi(\pi, \cdot)$, and the red line shows the depositors expected return $\Pi_{e}(\pi, \cdot)=d_{0}+\frac{\Pi}{2}$ under 
capital requirement, which consists of two terms:

- The deposit payment $d_{0}$;

- The dividend of equity holdings $\frac{\Pi}{2}$, which is only achieved in the good state, and its value is determined by

$$
\frac{\Pi}{2}=\frac{\gamma E\left[R_{H}\right]-d_{0}}{2}=\frac{\gamma E\left[R_{H}\right]-\frac{1-k}{1+k} \gamma E\left[R_{H}\right]}{2}=\frac{k}{1+k} \gamma E\left[R_{H}\right] .
$$

Denote the intersection of $\Pi_{e}(\pi, \cdot)=d_{0}+\frac{\Pi}{2}$ and $\gamma E\left[R_{L}\right]$ by $A$, which is equal to (see Appendix A.4 for detail)

$$
A=\frac{2\left(R_{1}-p_{L} R_{2}\right)}{(1-\gamma) R_{1}+\left(\gamma-p_{L}\right) R_{2}}
$$

as well as the intersection of $\Pi_{e}(\pi, \cdot)=d_{0}+\frac{\Pi}{2}$ and $\gamma E\left[R_{H}\right] \pi+(1-\pi) c$ by $B$, which is equal to (see Appendix A.4 for detail)

$$
B=\frac{2\left[(1-\gamma)\left(c R_{1}-p_{L} R_{1} R_{2}\right)+\left(\gamma-p_{H}\right)\left(c R_{2}-R_{1} R_{2}\right)\right]}{2(1-\gamma) c R_{1}+2\left(\gamma-p_{H}\right) c R_{2}+\left[\gamma\left(p_{H}-1\right)-\left(\gamma-p_{H}\right)-(1-\gamma) p_{L}\right] R_{1} R_{2}} .
$$

Now it's straight forward to compare investor's payoff under equity requirements with the laissez faire free riding equilibrium for some extreme values:

Lemma 4.1 The depositors' expected return under equity requirement is lower than the laissez-faire outcome when $\pi=0$ or $\pi=1$.

Proof See Appendix A.3.

The intuition of Lemma 4.1 is straight forward: There is no uncertainty when $\pi=0$ or $\pi=1$, so it's inferior to hold costly equities as we already explained before.

Then Proposition 4.2 characterizes the welfare improvement of introducing equity requirements. 
Proposition 4.2 Given equity requirement $k$ imposed by the regulator,

- When $A \in\left(0, \bar{\pi}_{1}\right]$, i.e.

$$
\left(2 \gamma R_{2}-\gamma E\left[R_{H}\right]-d_{0}\right)\left(\gamma E\left[R_{L}\right]-d_{0}\right)+\left(2 \gamma E\left[R_{L}\right]-\gamma E\left[R_{H}\right]-d_{0}\right)\left(d_{0}-c\right) \leq 0,
$$

then $S=[A, B] \supseteq\left[\bar{\pi}_{1}, \bar{\pi}_{2}\right]$;

- When $A \in\left(\bar{\pi}_{1}, \bar{\pi}_{2}\right]$, i.e.

$$
\left(2 \gamma R_{2}-\gamma E\left[R_{H}\right]-d_{0}\right)\left(\gamma E\left[R_{L}\right]-d_{0}\right)+\left(2 \gamma E\left[R_{L}\right]-\gamma E\left[R_{H}\right]-d_{0}\right)\left(d_{0}-c\right)>0,
$$

and

$$
\gamma\left(E\left[R_{H}\right]-E\left[R_{L}\right]\right)\left(d_{0}-c\right) \geq\left(\gamma E\left[R_{H}\right]-c\right)\left(\gamma E\left[R_{L}\right]-d_{0}\right),
$$

then $S=[\tilde{\pi}, B]$ in which $\tilde{\pi} \in\left(\bar{\pi}_{1}, \bar{\pi}_{2}\right]$ and $S \cap\left[\bar{\pi}_{1}, \bar{\pi}_{2}\right]=\left[\tilde{\pi}, \bar{\pi}_{2}\right]$;

- When $A \in\left(\bar{\pi}_{2}, 1\right]$, i.e.

$$
2\left(\gamma E\left[R_{L}\right]-d_{0}\right)\left(\gamma E\left[R_{H}\right]-c\right) \geq\left(\gamma E\left[R_{H}\right]-d_{0}\right)\left(\gamma E\left[R_{L}\right]-c\right),
$$

then $S \subseteq[\tilde{\pi}, B]$ in which $\tilde{\pi} \in\left(\bar{\pi}_{1}, \bar{\pi}_{2}\right]$ and $S \cap\left[\bar{\pi}_{1}, \bar{\pi}_{2}\right]=\left[\tilde{\pi}, \bar{\pi}_{2}\right]$.

Proof See Appendix A.4.

The three possible cases are characterised in Figure 5, 6 and 7, respectively. Numerical examples simulating these cases are presented in the ApPEndix B.

Equity requirements give investors a higher payoff than the laissez-faire market outcome whenever their payoff with a safe bank holding sufficient equity exceeds the payoff of the mixed strategy equilibrium with free riding banks for all parameter values. This case is captured as case 1 , shown in Figure 5. Since free riding partly destroys the value of deposits held by prudent banks (forcing them to hold a riskier portfolio), it seems obvious that imposing equity requirements will always dominate the laissez-faire outcome with mixed strategies. Unfortunately, this need not be the case. It is quite likely that equity requirements result in inferior payoffs for some range of parameter values (as shown in case 2 - see Figure 6). It might even 
be that imposing equity requirements makes investors worse than laissezfaire for all parameter values. This is shown in FIgURE 7, representing case 3.

The intuition behind this at first surprising result is that holding equity can be quite costly; if so, it may be superior to accept the fact that systemic risk is a price to be paid for higher returns on average. It should be evident that narrow banking (imposing the requirement that banks hold sufficient equity so as to be able to pay out demand deposits in all states of the world) can be quite inferior: If the bad state is a rare probability event, it simply makes no sense to dispense with all the efficiency gains out of banking with deposit contracts.

The mix of liquidity requirements with lender of last resort policy is always dominating equity requirements. See FIGURE 8. The reason is as following: Consider that the banks are required to hold $\underline{\alpha}=\alpha\left(p_{H}\right)$ when $\pi$ is high. Then when $p_{H}$ reveals, the investor's real return is $\gamma E\left[R_{H}\right]$; and when $p_{L}$ reveals, the investor's real return is $\alpha\left(p_{H}\right) R_{1}+\left(1-\alpha\left(p_{H}\right)\right) p_{L} R_{2}$. Therefore the investor's overall expected return turns out to be

$$
\Pi_{m}=\gamma E\left[R_{H}\right] \pi+(1-\pi)\left[\alpha\left(p_{H}\right) R_{1}+\left(1-\alpha\left(p_{H}\right)\right) p_{L} R_{2}\right],
$$

which is linear in $\pi$, as the green line of Figure 8 shows. Note that when $\pi=$ $1, \Pi_{m}=\gamma E\left[R_{H}\right]>d_{0}+\frac{\Pi}{2}$; and when $\pi=0, \Pi_{m}=\alpha\left(p_{H}\right) R_{1}+\left(1-\alpha\left(p_{H}\right)\right) p_{L} R_{2}=d_{0}$. Therefore, $\Pi_{m}$ line is above $d_{0}+\frac{\Pi}{2}, \forall \pi \in(0,1]$, i.e. the mix of liquidity requirements with lender of last resort policy is always dominating equity requirements when aggregate uncertainty exists.

In our simple model with just two feasible aggregate states, narrow banking is equivalent to imposing equity requirements. After all, the only role for equity here is to provide a cushion in the bad state of the world. Things get more interesting in a realistic setting with a continuous probability distribution. In that case, narrow banking would boil down to requiring sufficient equity even for the worst case, whereas equity requirements allow much 


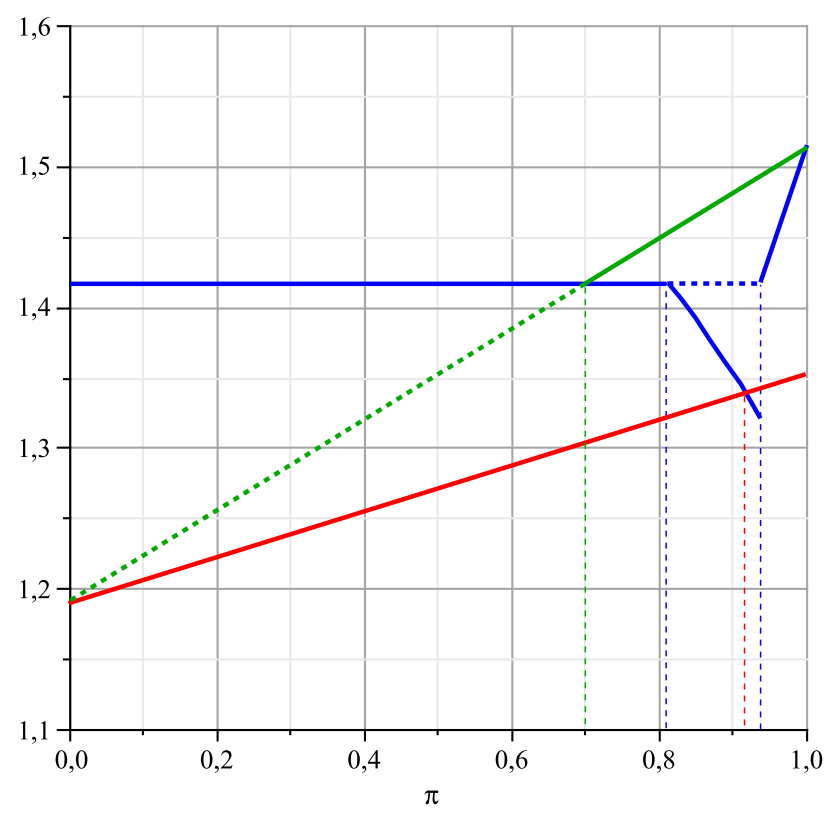

Fig. 8. Expected return with credible liquidity injections (for the case of FIGURE B.3) more flexibility, taking precautions for the most likely events. To analyse that issue is left for future research.

\section{Conclusion}

Traditionally, aggregate liquidity shocks have been modelled as exogenous events. In this paper, we derive the aggregate share of liquid projects endogenously. It depends on the incentives of financial intermediaries to invest in risky, illiquid projects. This endogeneity allows us to capture the feedback between financial market regulation and incentives of private banks, determining the aggregate amount of liquidity available.

We model (real) illiquidity in the following way: liquid projects are realised early. Illiquid projects promise a higher return, but a stochastic fraction of these type of projects will be realised late. We concentrate on pure illiquidity risk: There will never be insolvency unless triggered by illiquidity (by a bank run). Financial intermediaries choose the share invested in high 
yielding but less liquid assets. As a consequence of limited liability, banks are encouraged to free ride on liquidity provision. Relying on sufficient liquidity provided by the market, they are inclined to invest excessively in illiquid long term projects.

Liquidity provision by central banks can help to prevent bank runs with inefficient early liquidation. In Cao \& Illing (2007), we showed that the anticipation of unconditional liquidity provision results in overinvestment in risky activities (moral hazard), creating excessive systemic risk.

Extending our previous work, this paper analyses the adequate policy response to endogenous systemic liquidity risk, providing a cost / benefit analysis of different forms of banking regulation to better to understand what type of intervention is required. We explicitly compare the impact both of liquidity and capital requirements. We show that it is crucial for efficient lender of last resort policy to impose ex ante minimum liquidity standards for banks. In addition, we analyse the impact of equity requirements and narrow banking in the following sense: banks are required to hold sufficient liquid funds so as to pay out in all contingencies. We prove that such a policy is strictly inferior to imposing minimum liquidity standards ex ante combined with lender of last resort policy. It is even likely to be inferior relative to the outcome of a mixed strategy equilibrium with free riding banks.

In our model with just two feasible aggregate states, narrow banking is equivalent to imposing equity requirements. The only role for equity here is to provide a cushion in the bad state of the world. In a realistic setting with a continuous probability distribution, narrow banking would boil down to requiring sufficient equity even for the worst case, whereas equity requirements allow more flexibility. We leave it for future research to analyse that issue. Following Diamond \& Rajan (2006), we model financial intermediation via traditional banks offering fragile deposit contracts. Systemic risk is triggered by bank runs. In modern economies, a significant part of intermediation is provided by the shadow banking sector. These institutions (like 
hedge funds and investment banks) are not financed via deposits, but they are highly leveraged. Incentives to dance (to free ride on liquidity provision) seem to be even stronger for the shadow banking industry. So imposing liquidity requirements only for the banking sector will not be sufficient to cope with free riding. In future work, we plan to analyse incentives for leveraged institutions within our framework. 


\section{Appendix}

\section{A Proofs}

\section{A.1 Proof of Proposition 2.1}

The mixed strategy equilibrium is characterised as Proposition 2 of Cao \& Illing (2007). By chooseing $\alpha_{s}^{*}$ a prudent bank should have equal return at both states, $d_{0}^{s}=d_{0}^{s}\left(p_{H}\right)=d_{0}^{s}\left(p_{L}\right)$, i.e.

$$
\begin{aligned}
& \gamma\left[\alpha_{s}^{*} R_{1}+\left(1-\alpha_{s}^{*}\right) p_{H} R_{2}+\frac{\left(1-\alpha_{s}^{*}\right)\left(1-p_{H}\right) R_{2}}{r_{H}}\right] \\
= & \gamma\left[\alpha_{s}^{*} R_{1}+\left(1-\alpha_{s}^{*}\right) p_{L} R_{2}+\frac{\left(1-\alpha_{s}^{*}\right)\left(1-p_{L}\right) R_{2}}{r_{L}}\right] .
\end{aligned}
$$

With some simple algebra this is equivalent to

$$
\frac{1}{r_{H}}=\frac{1-p_{L}}{1-p_{H}} \frac{1}{r_{L}}-\frac{p_{H}-p_{L}}{1-p_{H}}
$$

Plot $\frac{1}{r_{H}}$ as a function of $\frac{1}{r_{L}}$ as Figure A.1x shows:

The slope $\frac{1-p_{L}}{1-p_{H}}>1$ and intercept $-\frac{p_{H}-p_{L}}{1-p_{H}}<0$, and the line goes through $(1,1)$. But $r_{H}=r_{L}=1$ cannot be equilibrium outcome here, because $\alpha\left(p_{L}\right)$ is dominant strategy in this case and subject to deviation. So whenever $r_{H}>1$ (suppose $\frac{1}{r_{H}}=A$ in the graph), there must be $r_{H}>r_{L}>1$ (because $\left.\frac{1}{r_{H}}<\frac{1}{r_{L}}=B<1\right)$.

At $p_{L}$, given that $r_{L}>1$ the prudent bank's return is equal to $d_{0}^{s}=$ $\kappa\left(\alpha_{s}^{*}\left(p_{L}, r_{L}\right)\right)<\kappa\left(\alpha\left(p_{L}\right)\right)$, since the latter maximises the bank's expected return with $r^{*}=1$ by Lemma 2 of Cao \& Illing (2007). Therefore in the mixed strategy equilibrium, investors are worse off than if all banks would coordinate on the prudent strategy $\alpha\left(p_{L}\right)$. 


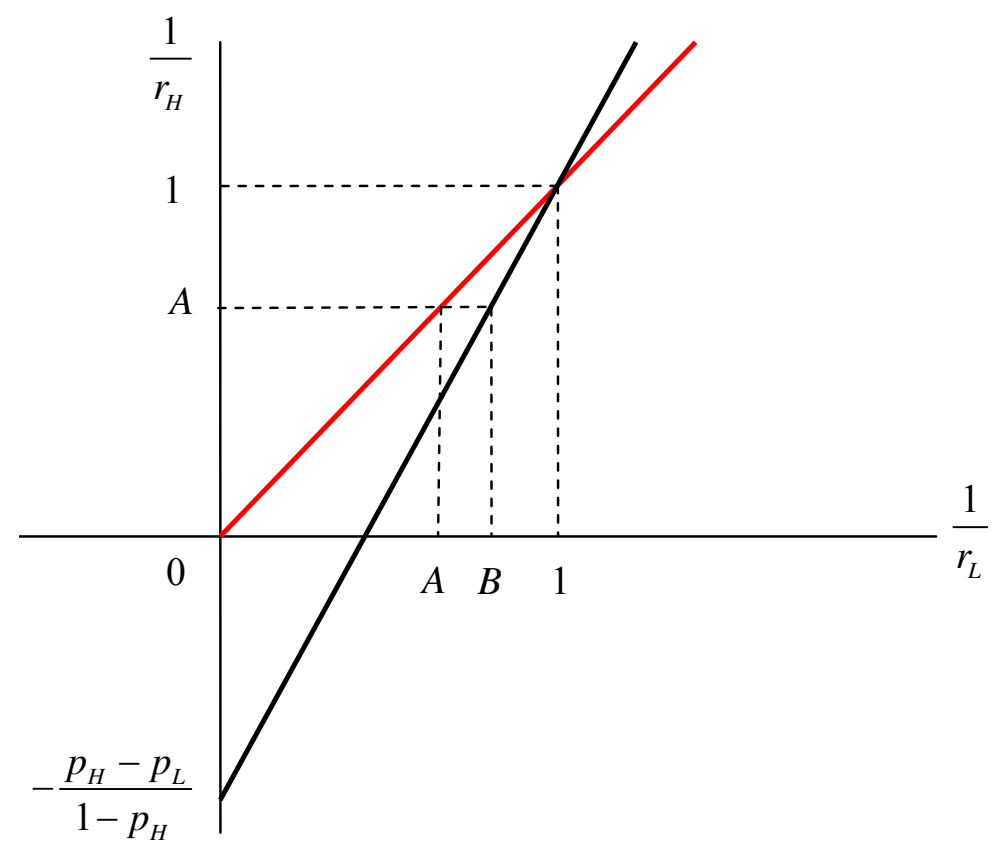

Fig. A.1. Higher interest rates in the mixed strategy equilibrium

\section{A.2 Proof of Proposition 3.1}

Suppose that a representative bank chooses to be prudent with $\alpha_{i}=\underline{\alpha}$, and promises a nominal deposit contract $d_{0}^{i}=\gamma\left[\underline{\alpha} R_{1}+(1-\underline{\alpha}) R_{2}\right]$ in order to maximize its investors return. Then when the bad state with high liquidity needs is realized, the central bank has to inject enough liquidity into the market to keep interest rate at $r=1$ in order to ensure bank $i$ 's survival. However, given $r=1$, a naughty bank $j$ can always profit from setting $\alpha_{j}=0$, promising the nominal return $d_{0}^{j}=\gamma R_{2}>d_{0}^{i}$ to its investors. Thus, surely the banks prefer to play naughty.

For those parameter values such that $\pi p_{H} R_{2}+(1-\pi) c<1$ there exists no equilibrium with liquidity injection. The reason is the following:

(1) Any symmetric strategic profile cannot be equilibrium, because

(a) If there is no trade under such strategic profile, i.e. $\alpha$ is so small that the real return is less than 1 , one bank can deviate by setting 
$\alpha=1$ and trading with investors;

(b) If there is trade under such strategic profile, i.e. $\alpha>0$ for all the banks, then one bank can deviate by setting $\alpha=0$ and getting higher nominal return than the other banks.

(2) Any asymmetric strategic profile, or profile of mixed strategies, cannot be equilibrium, because

(a) If there is no trade under such strategic profile, then the argument of 1 a) applies here;

(b) If there is trade under such strategic profile, then one bank can deviate by choosing a pure strategy, $\alpha=0$, and get better off there is no reason to mix with the other dominated strategies.

\section{A.3 Proof of Lemma 4.1}

When $\pi=0$,

$$
\begin{aligned}
d_{0}+\frac{\Pi}{2} \cdot 0 & =\alpha\left(p_{H}\right) R_{1}+\left(1-\alpha\left(p_{H}\right)\right) p_{L} R_{2} \\
& <\alpha\left(p_{L}\right) R_{1}+\left(1-\alpha\left(p_{L}\right)\right) p_{L} R_{2} \\
& =\gamma E\left[R_{L}\right]
\end{aligned}
$$

When $\pi=1$,

$$
\begin{aligned}
d_{0}+\frac{\Pi}{2} & =\frac{\alpha\left(p_{H}\right) R_{1}+\left(1-\alpha\left(p_{H}\right)\right) p_{L} R_{2}+\alpha\left(p_{H}\right) R_{1}+\left(1-\alpha\left(p_{H}\right)\right) p_{H} R_{2}}{2} \\
& <\alpha\left(p_{H}\right) R_{1}+\left(1-\alpha\left(p_{H}\right)\right) p_{H} R_{2} \\
& =\gamma E\left[R_{H}\right] . \quad
\end{aligned}
$$

\section{A.4 Proof of Proposition 4.2}

Generically, there are three cases concerning the relative positions of $\Pi(\pi, \cdot)$ and $\Pi_{e}(\pi, \cdot)$ : 
(1) As Figure 5 shows, the intersection $A$ lies between 0 and $\bar{\pi}_{1}$;

(2) As Figure 6 shows, the intersection $A$ lies between $\bar{\pi}_{1}$ and $\bar{\pi}_{2}$;

(3) As Figure 7 shows, the intersection $A$ lies between $\bar{\pi}_{2}$ and 1.

The intersection $A$ takes the value of $\pi$, such that

$$
\gamma E\left[R_{L}\right]=d_{0}+\frac{\Pi}{2}
$$

Solve to get

$$
A=\frac{2\left(\gamma E\left[R_{L}\right]-d_{0}\right)}{\gamma E\left[R_{H}\right]-d_{0}}=\frac{2\left(R_{1}-p_{L} R_{2}\right)}{(1-\gamma) R_{1}+\left(\gamma-p_{L}\right) R_{2}} .
$$

The intersection $B$ takes the value of $\pi$, such that

$$
\gamma E\left[R_{H}\right] \pi+(1-\pi) c=d_{0}+\frac{\Pi}{2}
$$

Solve to get

$$
\begin{aligned}
B & =\frac{d_{0}-c}{\frac{\gamma E\left[R_{H}\right]+d_{0}}{2}-c} \\
& =\frac{2\left[(1-\gamma)\left(c R_{1}-p_{L} R_{1} R_{2}\right)+\left(\gamma-p_{H}\right)\left(c R_{2}-R_{1} R_{2}\right)\right]}{2(1-\gamma) c R_{1}+2\left(\gamma-p_{H}\right) c R_{2}+\left[\gamma\left(p_{H}-1\right)-\left(\gamma-p_{H}\right)-(1-\gamma) p_{L}\right] R_{1} R_{2}} .
\end{aligned}
$$

Then the set $S$ can be determined in each case:

(1) As Figure 5 shows, when $A \in\left(0, \bar{\pi}_{1}\right]$,

$$
\frac{2\left(\gamma E\left[R_{L}\right]-d_{0}\right)}{\gamma E\left[R_{H}\right]-d_{0}} \leq \bar{\pi}_{1}=\frac{\gamma E\left[R_{L}\right]-c}{\gamma R_{2}-c},
$$

rearrange to get

$$
\begin{aligned}
& \left(2 \gamma R_{2}-\gamma E\left[R_{H}\right]-d_{0}\right)\left(\gamma E\left[R_{L}\right]-d_{0}\right)+\left(2 \gamma E\left[R_{L}\right]-\gamma E\left[R_{H}\right]-d_{0}\right)\left(d_{0}-c\right) \\
\leq & 0 .
\end{aligned}
$$


Since $\prod_{e}(\pi, \cdot)$ is strictly increasing in $\pi$, then

$$
\begin{aligned}
& \left.\Pi_{e}(\pi, \cdot)\right|_{\pi=B}>\left.\Pi_{e}(\pi, \cdot)\right|_{\pi=A} \geq\left.\gamma E\left[R_{L}\right]\right|_{\pi=\bar{\pi}_{1}}=\left.\left(\gamma E\left[R_{H}\right] \pi+(1-\pi) c\right)\right|_{\pi=\bar{\pi}_{2}} \\
\geq & \left.\Pi(\pi, \cdot)\right|_{\pi \in\left[\bar{\pi}_{1}, \bar{\pi}_{2}\right]},
\end{aligned}
$$

which implies $S=[A, B] \supseteq\left[\bar{\pi}_{1}, \bar{\pi}_{2}\right]$;

(2) As Figure 6 shows, when $A \in\left(\bar{\pi}_{1}, \bar{\pi}_{2}\right]$,

$$
\bar{\pi}_{1}=\frac{\gamma E\left[R_{L}\right]-c}{\gamma R_{2}-c}<\frac{2\left(\gamma E\left[R_{L}\right]-d_{0}\right)}{\gamma E\left[R_{H}\right]-d_{0}},
$$

rearrange to get

$$
\text { >0. }\left(2 \gamma R_{2}-\gamma E\left[R_{H}\right]-d_{0}\right)\left(\gamma E\left[R_{L}\right]-d_{0}\right)+\left(2 \gamma E\left[R_{L}\right]-\gamma E\left[R_{H}\right]-d_{0}\right)\left(d_{0}-c\right)
$$

What's more, in this case $B \in\left[\bar{\pi}_{2}, 1\right]$, and this is equivalent to

$$
\frac{\gamma E\left[R_{L}\right]-c}{\gamma E\left[R_{H}\right]-c}=\bar{\pi}_{2}<\frac{d_{0}-c}{\frac{\gamma E\left[R_{H}\right]+d_{0}}{2}-c}
$$

rearrange to get

$$
\gamma\left(E\left[R_{H}\right]-E\left[R_{L}\right]\right)\left(d_{0}-c\right) \geq\left(\gamma E\left[R_{H}\right]-c\right)\left(\gamma E\left[R_{L}\right]-d_{0}\right) .
$$

Similarly,

$$
\begin{aligned}
& \left.\prod_{e}(\pi, \cdot)\right|_{\pi \leq A} \leq\left.\gamma E\left[R_{L}\right]\right|_{\pi=\bar{\pi}_{1}}=\left.\left(\gamma E\left[R_{H}\right] \pi+(1-\pi) c\right)\right|_{\pi=\bar{\pi}_{2}} \leq\left.\Pi(\pi, \cdot)\right|_{\pi \in\left[\bar{\pi}_{2}, B\right]} \\
\leq & \left.\Pi_{e}(\pi, \cdot)\right|_{\pi \geq B}
\end{aligned}
$$

which implies $S=[\tilde{\pi}, B]$ in which $\tilde{\pi} \in\left(\bar{\pi}_{1}, \bar{\pi}_{2}\right]$ and $S \cap\left[\bar{\pi}_{1}, \bar{\pi}_{2}\right]=\left[\tilde{\pi}, \bar{\pi}_{2}\right]$;

(3) As Figure 7 shows, when $A \in\left(\bar{\pi}_{2}, 1\right]$,

$$
\bar{\pi}_{2}=\frac{\gamma E\left[R_{L}\right]-c}{\gamma E\left[R_{H}\right]-c}<\frac{2\left(\gamma E\left[R_{L}\right]-d_{0}\right)}{\gamma E\left[R_{H}\right]-d_{0}},
$$

rearrange to get

$$
2\left(\gamma E\left[R_{L}\right]-d_{0}\right)\left(\gamma E\left[R_{H}\right]-c\right) \geq\left(\gamma E\left[R_{H}\right]-d_{0}\right)\left(\gamma E\left[R_{L}\right]-c\right) .
$$

Similarly,

$$
\left.\Pi_{e}(\pi, \cdot)\right|_{\pi \leq B}<\left.\Pi_{e}(\pi, \cdot)\right|_{\pi \geq A} \leq\left.\gamma E\left[R_{L}\right]\right|_{\pi=\bar{\pi}_{1}}=\left.\left(\gamma E\left[R_{H}\right] \pi+(1-\pi) c\right)\right|_{\pi=\bar{\pi}_{2}},
$$


which implies $S \subseteq[\tilde{\pi}, B]$ in which $\tilde{\pi} \in\left(\bar{\pi}_{1}, \bar{\pi}_{2}\right]$ and $S \cap\left[\bar{\pi}_{1}, \bar{\pi}_{2}\right]=$ $\left[\tilde{\pi}, \bar{\pi}_{2}\right]$.

\section{B Results of numerical simulations}

The following figures present numerical simulations representing the three different cases.

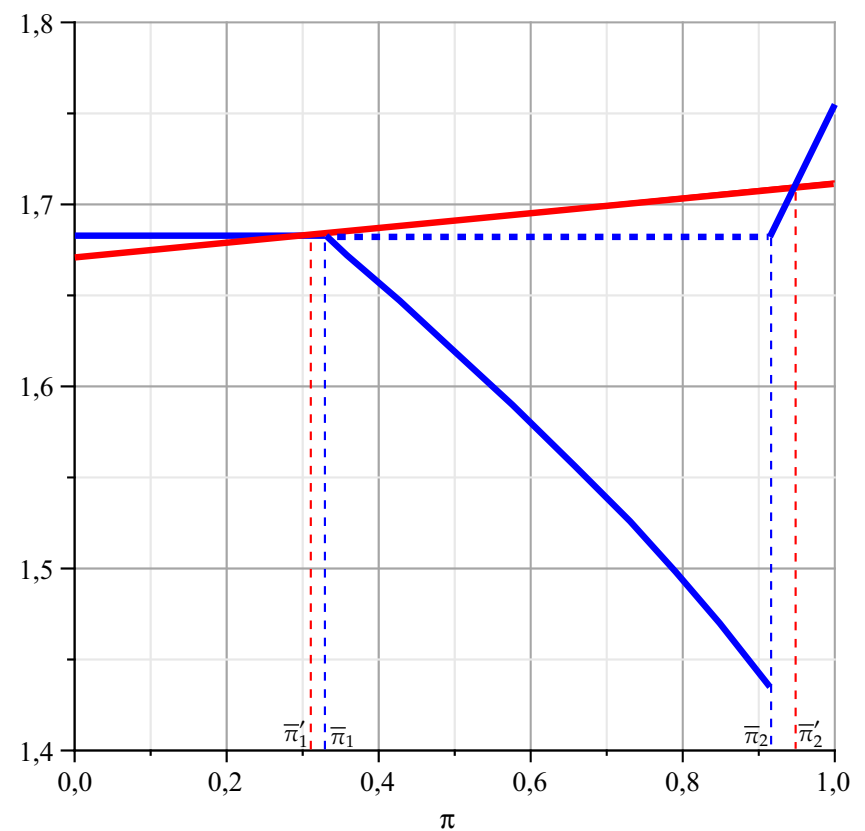

Fig. B.1. Expected return with / without equity, with $p_{H}=0.3, p_{L}=0.25, \gamma=0.6$, $R_{1}=1.8, R_{2}=5.5, c=0.9$ 


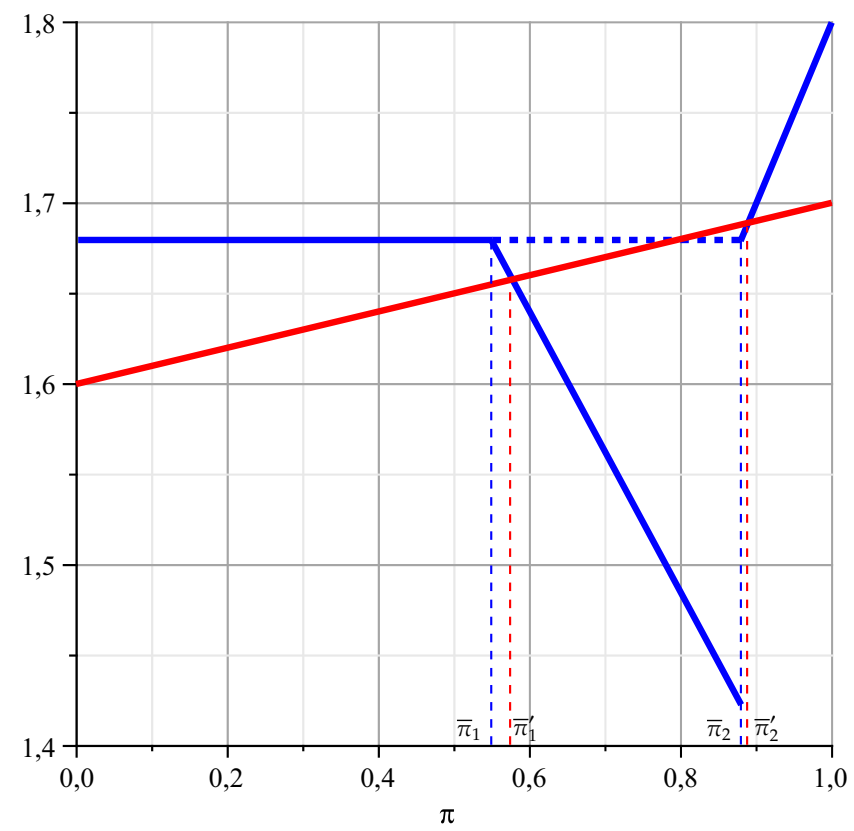

Fig. B.2. Expected return with / without equity, with $p_{H}=0.4, p_{L}=0.3, \gamma=0.6$, $R_{1}=2, R_{2}=4, c=0.8$

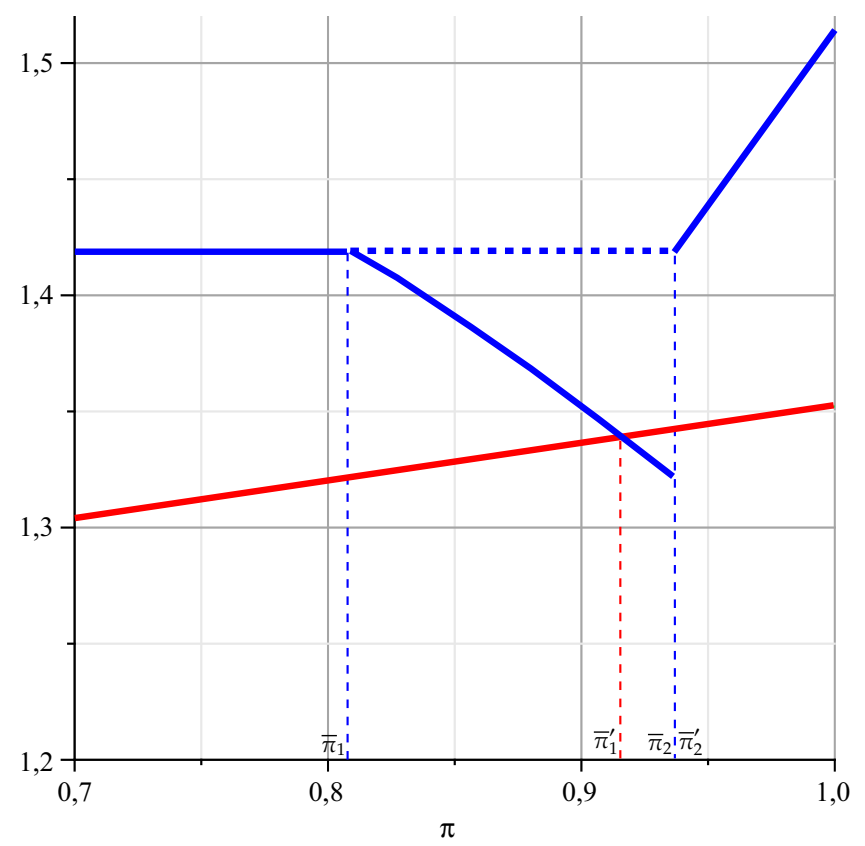

Fig. B.3. Expected return with / without equity, with $p_{H}=0.5, p_{L}=0.25, \gamma=0.7$, $R_{1}=1.8, R_{2}=2.5, c=0$ 


\section{References}

Allen, F., And D. Gale (1998): “Optimal financial crises”. Journal of Finance, 53, 1245-84.

Allen, F., And D. Gale (2004): "Financial intermediaries and markets". Econometrica, 72, 1023-1061.

Allen, F., And D. Gale (2007): Understanding Financial Crisis, Clarendon Lectures, New York: Oxford University Press.

Ваgенот, W. (1873): "A general view of Lombard Street". Reprinted in: Goodhard, C. and G. Illing (eds., 2002), Financial Crises, Contagion, and the Lender of Last Resort: A Reader, New York: Oxford University Press.

Buiter, W. H. ANd A. C. Sibert (2007): “The central bank as market maker of last resort". http://blogs.ft.com/maverecon/2007/08/the-central-banhtml/.

CAO, J. AND G. Illing (2007): “Liquidity shortages and monetary policy”. CESifo Working Paper Series No. 2210, available at SSRN: http://ssrn.com/abstract=1090825.

Diamond, D. W., ANd P. H. Dybvig (1983): “Bank runs, deposit insurance, and liquidity". Journal of Political Economy, 91, 401-419.

Diamond, D. W., ANd R. G. Rajan (2000): "A theory of bank capital". Journal of Finance, 55, 2431-2465.

Diamond, D. W., aNd R. G. Rajan (2001): “Liquidity risk, liquidity creation and financial fragility: A theory of banking". Journal of Political Economy, 109, 287-327.

Diamond, D. W., and R. G. Rajan (2005): “Liquidity shortage and banking crises". Journal of Finance, 60, 30-53.

Diamond, D. W., AND R. G. Rajan (2006): "Money in the theory of banking". American Economic Review, 60, 615-647.

Goodhart, C., ANd G. Illing (2002): Financial Crises, Contagion, and the Lender of Last Resort: A Reader, New York: Oxford University Press.

Hart, O., AND J. Moore (1994): "A theory of debt based on the inalienability of human capital". Quarterly Journal of Economics, 109, 841-879.

Holmström, B., ANd J. Tirole (1998): "Private and public supply of liquidity". Journal of Political Economy, 106, 1-40. 